\title{
Morphometric Measurements of Safety Zones and Orientation Angles for Freehand Placement of Revision Screws in Atlas Lateral Mass
}

\author{
Serkan SIMSEK ${ }^{1}$, Uygur ER ${ }^{2}$, Erek OZTURK ${ }^{3}$, Kazim YIGITKANLI ${ }^{4}$ \\ ${ }^{1}$ Lokman Hekim University, School of Medicine, Department of Neurosurgery, Ankara, Turkey \\ ${ }^{2}$ Acıbadem Ankara Hospital, Department of Neurosurgery, Ankara, Turkey \\ ${ }^{3}$ Tekirdag Dr. Ismail Fehmi Cumalioglu City Hospital, Department of Neurosurgery, Tekirdag, Turkey \\ ${ }^{4}$ Medicana Bursa Hospital, Department of Neurosurgery, Bursa, Turkey \\ Corresponding author: Erek OZTURK erekozturk@gmail.com
}

\section{ABSTRACT}

AIM: To demonstrate the possibility of revision screw placement to the atlas, as well as define the safety zones and orientation angles.

MATERIAL and METHODS: This retrospective study analysed the records of four patients who were operated for AAI earlier. Because they needed revision of Atlas screws, they were re-operated after obtaining the measurements mentioned in this study. In addition, measurements of 50 healthy subjects were included in the study as the control group. Maximum screw lengths were also measured.

RESULTS: Safe zone in the ideal sagittal direction were wider. As the screw projection becomes more cephalic direction in the sagittal plane, the safe zone for the screw becomes narrower. With the sagittal angle moving forwards cranially, the screw length becomes longer.

CONCLUSION: Atlas lateral mass screws could be safely revised whenever needed. The fact that needs to be considered is that the angular range becomes narrower, and the screw length becomes longer when the screw is directed more cranially.

KEYWORDS: Atlantoaxial fixation, Atlas, C-1 lateral mass screw, Safe zone, Vertebral artery, Working area

\section{INTRODUCTION}

A tlantoaxial instability (AAI) is a potentially severe and progressive condition resulting from various pathologies, such as trauma, malformations, rheumatoid arthritis and infections (16). Untreated cases can result in myelopathy or even death (19). Therefore, restoring the stability of patients with AAl is a necessity. In the case of clinically or radiologically significant AAl, stabilisation of the atlantoaxial complex is one of the best treatment options. In 1987, Magerl introduced a transarticular screw technique for stabilisation of the C1-C2 complex (12). However, a high risk of vertebral artery (VA) injury in patients with a high-riding VA (HRVA) and a thin isthmus of the axis, as well as the need for a complete reduction before fixation are some disadvantages of this technique (13). Hence, to overcome these restrictions, Goel designed a new technique for C1-C2 stabilisation in 1994 by inserting screws in the lateral mass and $\mathrm{C} 2$ pedicle $(3,4)$. This technique was modified by Harms in 2001 by using polyaxial screws (8). Biomechanical tests demonstrated that the $\mathrm{C} 1-\mathrm{C} 2$ fixation by using this technique provided biomechanical properties similar to transarticular screw fixation (14). However, this technique is challenging and requires detailed anatomical knowledge of the atlas and surrounding structures. The surgeon needs to be aware of the screw entry points, safety zones of trajectory
Serkan SIMSEK (1) : 0000-0002-1773-7135

Uygur ER (10): 0000-0002-6641-0075
Erek OZTURK (10: :0000-0002-3799-9650

Kazim YIGITKANLI (D) : 0000-0003-0628-0173 
and proximity to VA. Moreover, screw length measurements before the operation is crucial. Despite all these advantages and stable construct, some patients might need a revision of the construct. This study aimed to demonstrate the possibility of revision screw placement, as well as define the safety zones and orientation angles.

\section{MATERIAL and METHODS}

\section{Subjects and Measurement Procedure}

This retrospective study analysed the records of four patients who were operated for AAl earlier. Because they needed revision of Atlas screws, they were re-operated after obtaining the measurements mentioned in this section. In addition, measurements of 50 healthy subjects were included in the study as the control group. Informed consent was obtained from all patients and healthy subjects. The study was approved by the institutional review board (Lokman Hekim University, April, 23 ${ }^{\text {rd }}$ 2020, Registration No: 2020/020 - Code No: 2020019). Computerised tomography angiography images were obtained using three-dimensional reformatting multiplanar reconstruction with Horos ${ }^{\mathrm{TM}}$ V.3.3.6 (the Horos Project, USA) image viewer software to demonstrate the possibility of revision screw placement to the lateral mass of the atlas. The right and left atlas lateral masses were evaluated separately in each patient. The screw projection (parallel to the atlas lateral mass inferior face; $\mathrm{ra}_{1}, \mathrm{rb}_{1}$ for values on the right and $l \mathrm{a}_{1}, \mathrm{lb}_{1}$ for values on the left), ideal angle $\left(15^{\circ}\right.$ parallel to the atlas lateral mass inferior face; $\mathrm{ra}_{2}, \mathrm{rb}_{2 ;}\left(\mathrm{l}_{2}, \mathrm{lb}_{2}\right)$ and maximum cephalic angle $\left(\mathrm{ra}_{3}, \mathrm{rb}_{3} ; \mathrm{la}_{3} \mathrm{Ib}_{3}\right)$ were measured in the sagittal plane, whereas the maximum lateral angle, maximum medial angle and maximum screw lengths were measured in the axial plane (3). The internal carotid artery (ICA) medial wall was taken as the maximum limit of the lateral angle, and the medial edge of the lateral mass was taken as the maximum limit of the medial angle. If the VA was more medial than ICA, VA was considered the border. In addition, the maximum cephalic angle in the sagittal plane was determined for each case. Maximum screw lengths were measured and compared with the ideal angle, endplate parallel projection and maximum cephalic angle (Figure 1A-C).

\section{Statistical Analysis}

Statistical analysis was performed using SPSS version 23 software (IBM Co., USA). Normal distribution of data was tested using Shapiro Wilk's test. The student's $t$-test was used for comparing properties that fit with normal distribution in two independent groups. A paired $t$-test was used for comparing measurements of the left and right sides. The left and right side measurements in different sagittal angles were compared using repeated-measures ANOVA test, and posthoc comparison of these was performed using Bonferroni correction. Age-related variability of measurements was tested using Pearson's correlation coefficient. Descriptive statistics used mean \pm standard deviation and minimum-maximum range for numerical variables and numbers and percentages (\%) for categorical variables. A p value less than 0.05 was considered statistically significant.

\section{RESULTS}

The mean age of the study population was $60.98 \pm 13.33$ years (32-95 years). The study population comprised $60 \%$ men and $40 \%$ women $(\mathrm{M} / \mathrm{F}=1.5)$. The mean angle measurements and ideal screw lengths are presented in Table I.

Upon comparing the left and right sides, $a_{1}+b_{1}$ values $\left(a_{1}\right.$ is angle between vertical axial line passes the entry point and the line represents maximal possible lateral screw trajectory; $b_{1}$ is angle between vertical axial line passes the entry point and the line represents maximal possible medial screw trajectory. Angles $a_{2}, b_{2}, a_{3}$ and $b_{3}$ are the same measurements in the different axial planes due to sagittal directions of the screws) on the left side were slightly higher than those on the right side, but this difference was not statistically significant $(p=0.143)$. Similarly, no differences between sides were noted regarding values obtained in the maximum cephalic position $(p=0.106)$. Values in the ideal position $\left(a_{2}+b_{2}\right)$ were higher on the right side, and this was statistically significant $(p<0.05)$. Both sides exhibited statistically significant differences among $a_{1}+b_{1}, a_{2}+b_{2}$ and $a_{3}+b_{3}$ values $(p<0.05)$. Upon post-hoc comparisons, $a_{3}+b_{3}$ values were noted to be significantly lower than $a_{1}+b_{1}$ and $a_{2}+b_{2}$ values $(p<0.005)$. Therefore, as

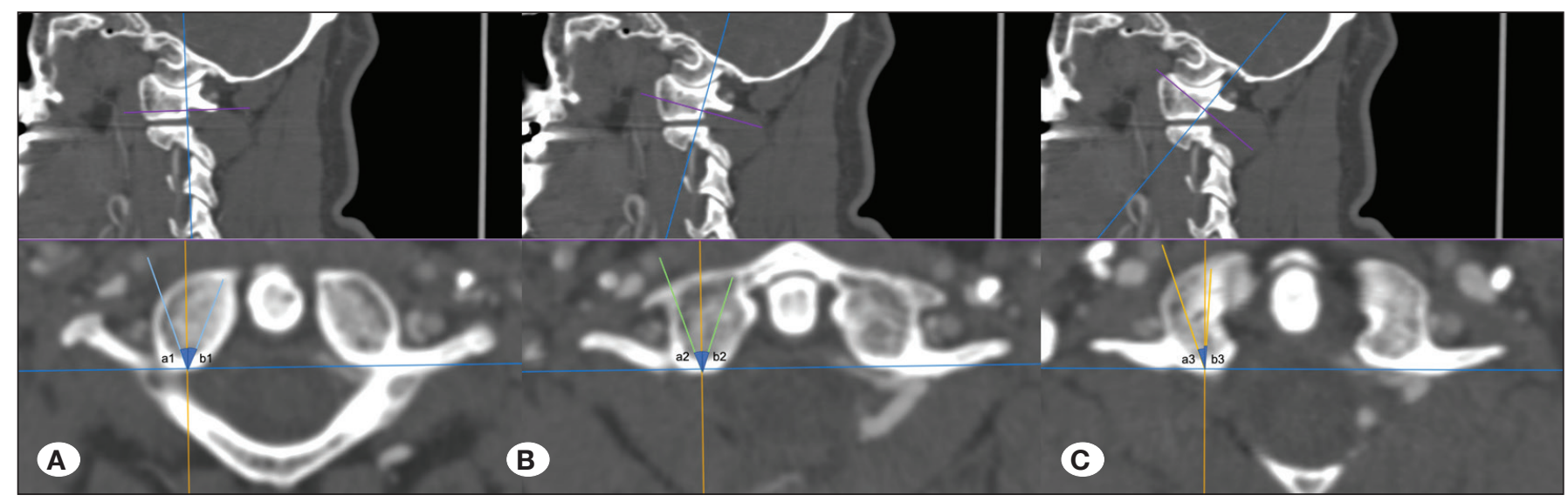

Figure 1: Measurements of lateral and medial angles parallel to the inferior face of the Atlas lateral mass (A), ideal cephalic sagittal angle (B) and maximum cephalic angle (C). 
Table I: Distribution of General Data Set

\begin{tabular}{|c|c|c|}
\hline & Min-Max & Mean \pm SD \\
\hline Ages & $32-95$ & $60.98 \pm 13.33$ \\
\hline $\mathrm{R}$ max lateral angle ra1 & $0.00-40.46$ & $14.75 \pm 8.41$ \\
\hline $\mathrm{R}$ max medial angle rb1 & $13.23-34.45$ & $20.35 \pm 4.23$ \\
\hline $\mathrm{R}$ ra1 screw length & $11.45-16.86$ & $14.73 \pm 1.41$ \\
\hline R rb1 screw length & $13.04-20.09$ & $17.55 \pm 1.34$ \\
\hline $\mathrm{L} \max \mathrm{la1}$ & $0.00-27.12$ & $14.53 \pm 7.50$ \\
\hline $\mathrm{L} \max \mathrm{lb} 1$ & $0.00-28.69$ & $22.10 \pm 4.43$ \\
\hline L la1 screw length & $11.40-16.92$ & $14.27 \pm 1.45$ \\
\hline L lb1 screw length & $15.20-19.43$ & $17.51 \pm 1.15$ \\
\hline $\mathrm{R}$ max ra2 & $0.00-35.31$ & $12.38 \pm 8.63$ \\
\hline $\mathrm{R}$ max rb2 & $14.42-28.26$ & $21.13 \pm 3.33$ \\
\hline $\mathrm{R}$ ra2 screw length & 12.19-18.20 & $15.39 \pm 1.35$ \\
\hline $\mathrm{R}$ rb2 screw length & $15.29-23.29$ & $18.23 \pm 1.46$ \\
\hline L max la2 & $0.00-28.05$ & $13.85 \pm 7.92$ \\
\hline $\mathrm{L} \max \mathrm{lb} 2$ & $12.06-30.12$ & $22.30 \pm 3.10$ \\
\hline L la2 screw length & $11.41-19.12$ & $15.05 \pm 1.65$ \\
\hline L lb2 screw length & $14.97-20.52$ & $18.04 \pm 1.34$ \\
\hline $\mathrm{R}$ max ra3 & $0.00-26.96$ & $12.32 \pm 6.63$ \\
\hline $\mathrm{R}$ max rb3 & $0.00-18.58$ & $7.67 \pm 5.96$ \\
\hline $\mathrm{R}$ ra3 screw length & $16.08-22.14$ & $19.22 \pm 1.53$ \\
\hline $\mathrm{R}$ rb3 screw length & $17.06-23.71$ & $21.15 \pm 1.49$ \\
\hline L max la3 & $0.00-24.65$ & $12.18 \pm 7.04$ \\
\hline $\mathrm{L} \max \mathrm{lb} 3$ & $0.00-20.74$ & $10.00 \pm 6.60$ \\
\hline L la3 screw length & $15.72-22.84$ & $18.73 \pm 1.58$ \\
\hline L lb3 screw length & $15.15-24.80$ & $21.14 \pm 1.88$ \\
\hline Maximum cephalic angle & $36.56-49.30$ & $43.88 \pm 3.46$ \\
\hline $\begin{array}{l}\text { Maximum screw length in } \\
\text { cephalic angle }\end{array}$ & $18.08-23.73$ & $20.73 \pm 1.55$ \\
\hline $\begin{array}{l}\text { Screw length in ideal } \\
\text { cephalic angle }\end{array}$ & 13.14-18.16 & $15.95 \pm 1.41$ \\
\hline $\begin{array}{l}\text { Screw length in parallel to } \\
\text { inferior end plate of atlas }\end{array}$ & $12.62-17.69$ & $15.10 \pm 1.40$ \\
\hline Male $\mathrm{n}(\%)$ & $30(60)$ & \\
\hline Female $\mathrm{n}(\%)$ & $20(40)$ & \\
\hline
\end{tabular}

Max lateral angle: angle (ICA medial wall is the lateral border); max medial angle (lateral mass medial edge is the medial border); ages are given as years old; lengths are given as $\mathrm{mm}$. the screw projection becomes more cephalic direction in the sagittal plane, the safe zone for the screw becomes narrower (Table II).

No statistically significant differences were noted between male and female patients ( $p>0.05$ ) (Table III). Notably, all angles became narrower with ageing; this finding is a statistical result of this study. However, these correlations were weak. One of the possible explanations may be that vertebral heights are decreasing with age. This impinges on the angles in sagittal and coronal plane. Axial angles don't be affected by ageing. Only moderate negative correlations were noted between left $a_{1}+b_{1}$ and $a_{2}+b_{2}$ zones with ageing $\left(r=-0.342, p=0,015\right.$ for $a_{1}$ $+b_{1}$ and $r=-0.301, p=0.034$ for $a_{2}+b_{2}$ ) (Table IV).

Furthermore, using a 95\% confidence interval, the error bars for the left and right sides are presented in graphs (Figure 2 and 3 ).

Notably, the ideal screw lengths of the right and left sides were not significantly different for any measurements $\left(\mathrm{a}_{1}+\right.$ $b_{1}, a_{2}+b_{2}$ and $\left.a_{3}+b_{3}\right),(p>0.05)$. Nevertheless, on the left side, screw lengths were significantly different in the three sagittal projections $(p<0.05)$. Post-hoc comparisons revealed that $a_{2}+b_{2}$ measurements were significantly shorter than the other two measurements $(p<0.001)$. On the right side, $a_{3}$ $+b_{3}$ screw lengths were significantly longer than the other two measurements upon post-hoc comparisons $(p<0.001)$. Therefore, with the sagittal angle moving forwards cranially, the screw length becomes longer (Table V).

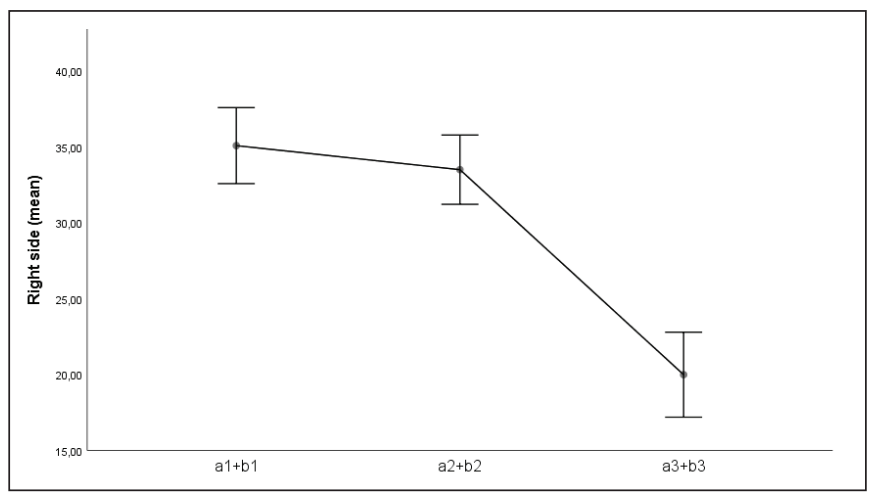

Figure 2: Right side error bars.

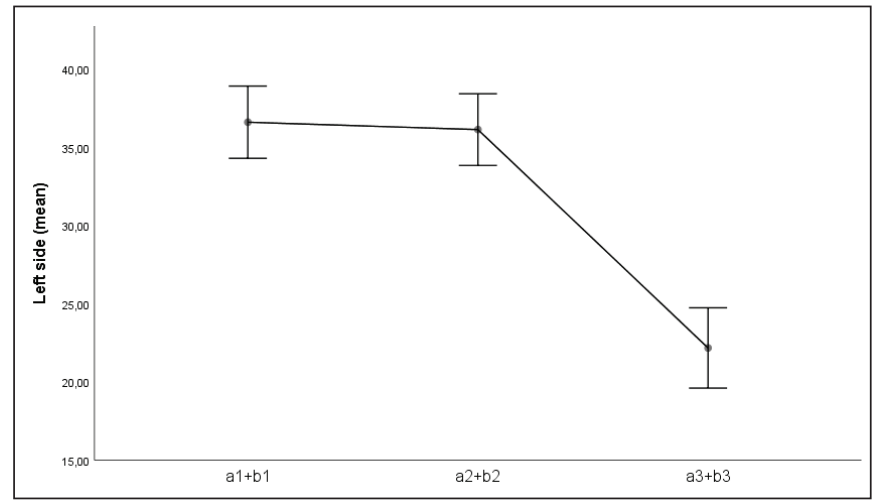

Figure 3: Left side error bars. 
Simsek S. et al: Revision Screws in Atlas Lateral Mass

Table II: Left/right Sides and Intragroup Comparisons of Parameters

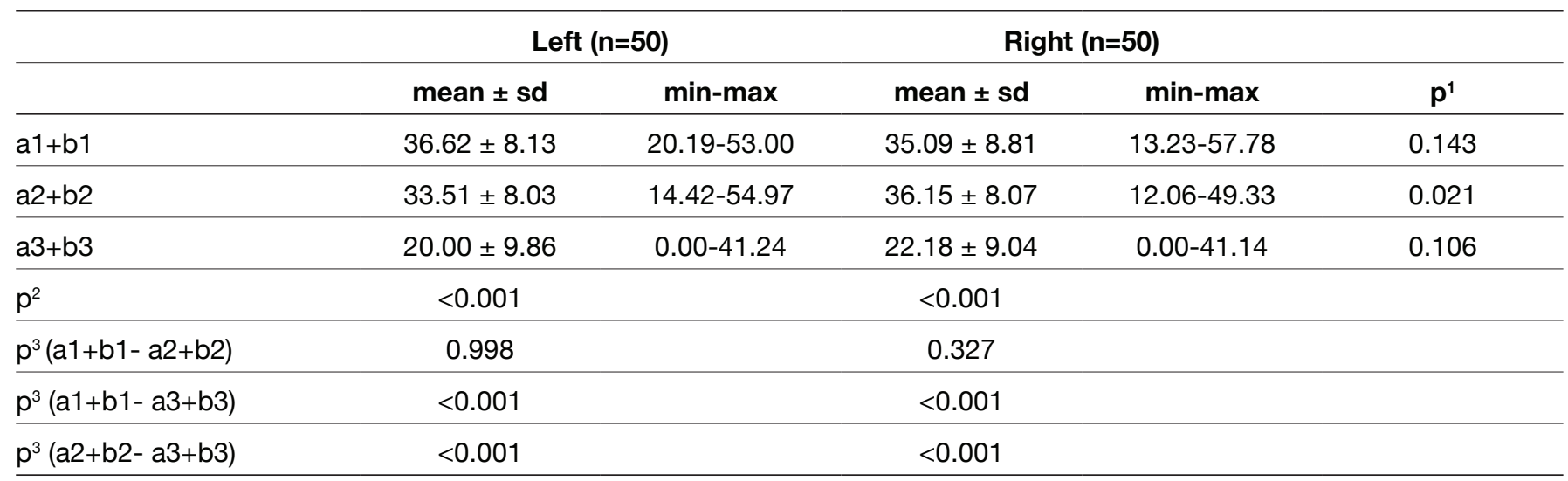

${ }^{1}$ Paired $t$ test, ${ }^{2}$ ANOVA in repetitive measurements, ${ }^{3}$ Bonferroni test, $p<0.05$ sd: standard deviation.

Table III: Comparison of Parameters For Gender

\begin{tabular}{|c|c|c|c|c|c|}
\hline & \multicolumn{2}{|c|}{ Male $(n=30)$} & \multicolumn{2}{|c|}{ Female $(n=20)$} & $\mathbf{p}$ \\
\hline Right a1+b1 & $34.14 \pm 8.89$ & $13.23-57.78$ & $36.53 \pm 8.7$ & $22.15-53.65$ & 0.352 \\
\hline Left a1+b1 & $35.77 \pm 8.76$ & $20.19-53.00$ & $37.91 \pm 7.1$ & $24.10-49.19$ & 0.367 \\
\hline Right a2+b2 & $34.58 \pm 8.4$ & $14.42-54.97$ & $31.89 \pm 7.33$ & $22.88-51.20$ & 0.249 \\
\hline Right a3+b3 & $21.67 \pm 9.88$ & $0.00-41.24$ & $17.48 \pm 9.52$ & $0.00-31.45$ & 0.143 \\
\hline Left a3+b3 & $23.01 \pm 9.3$ & $0.00-39.27$ & $20.93 \pm 8.71$ & $0.00-41.14$ & 0.430 \\
\hline
\end{tabular}

$p$ value was obtained from Student's $t$ test, $s d$ : standard deviation.

Table IV: Correlations Between Ages and Parameters

\begin{tabular}{|c|c|c|c|c|c|c|c|}
\hline & & $\mathrm{R} a 1+b 1$ & $L a 1+b 1$ & $\mathrm{R}$ a2+b2 & $\mathrm{L}$ a2+b2 & R a3+b3 & $L$ a3+b3 \\
\hline \multirow{2}{*}{ Ages } & $r$ & -0.059 & $-0.342^{*}$ & -0.238 & $-0.301^{*}$ & -0.035 & -0.085 \\
\hline & $p$ & 0.684 & 0.015 & 0.096 & 0.034 & 0.812 & 0.555 \\
\hline
\end{tabular}

r: Pearson's correlation coefficient.

Table V: Screw Length Right / Left and Intragroup Comparisons

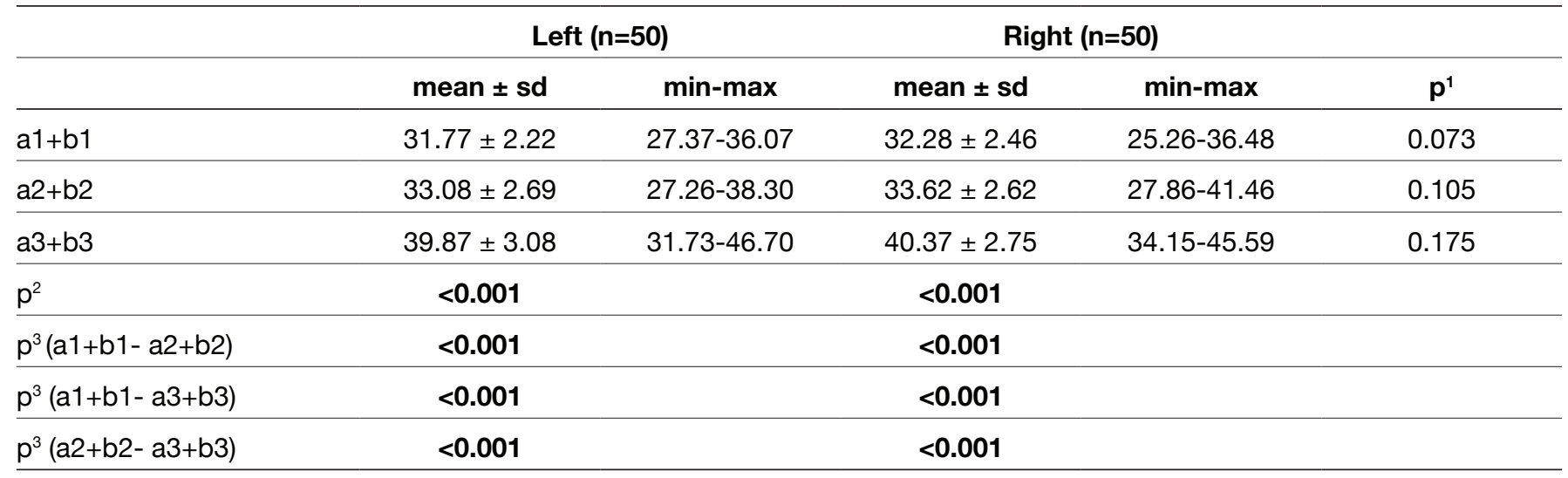

${ }^{1}$ Paired $t$ test, ${ }^{2}$ ANOVA for repetitive measurements, ${ }^{3}$ Bonferroni's test, $p<0.05$; sd: standard deviation. 


\section{Sample Cases}

Case 1: A 12-year-old girl with Down syndrome. The left atlas screw violated the canal. It was revised immediately (Figure $4 \mathrm{~A}, \mathrm{~B})$.

Case 2: A 34-year-old woman with os odontoideum. After 2 years, screws broke, and therefore, revised (Figure 5A-C).
Case 3: A 61-year-old woman with rheumatoid arthritis who had trauma. Malposition of screws was observed after fixation, but not revised. After 6 months, screws loosened and were revised (Figure 6A, B).

Case 4: A 42-year-old man with a sagittal imbalance. After 2 years, the atlas and axis screws broke and were revised.

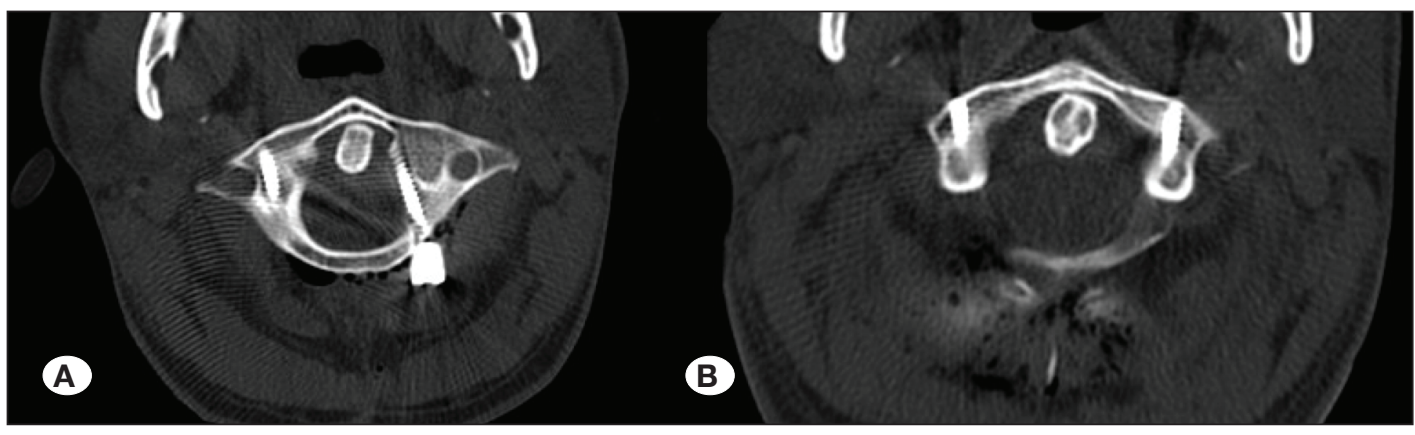

Figure 4: These figures are depicting case 1 . The left Atlas screw violates the canal (A), and after revision (B).

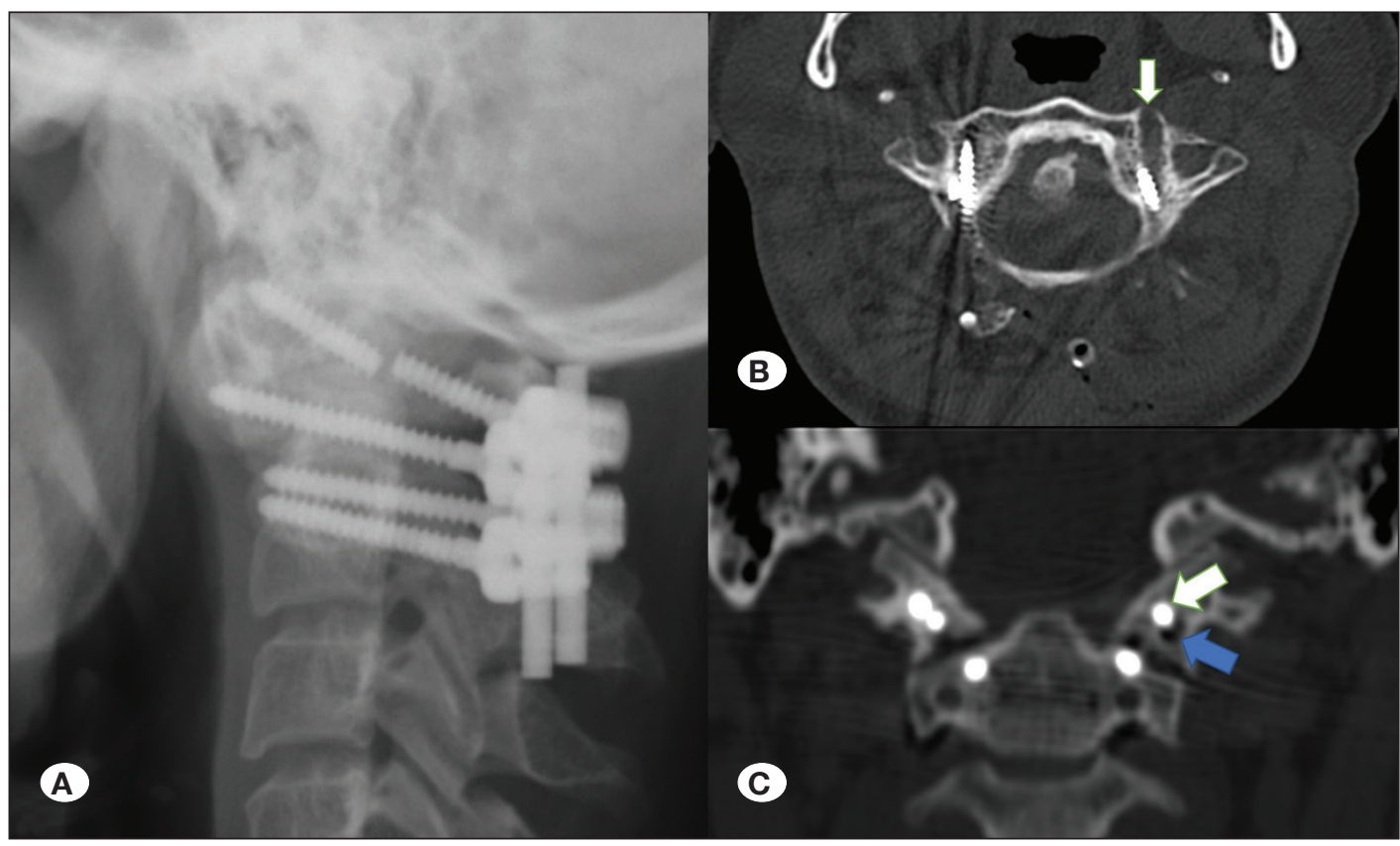

Figure 5: These figures are depicting case 2 . Broken Atlas screw (A), revised and old screw paths (B) and new screws and old entries (C). Arrows point to new screws and old entry points.

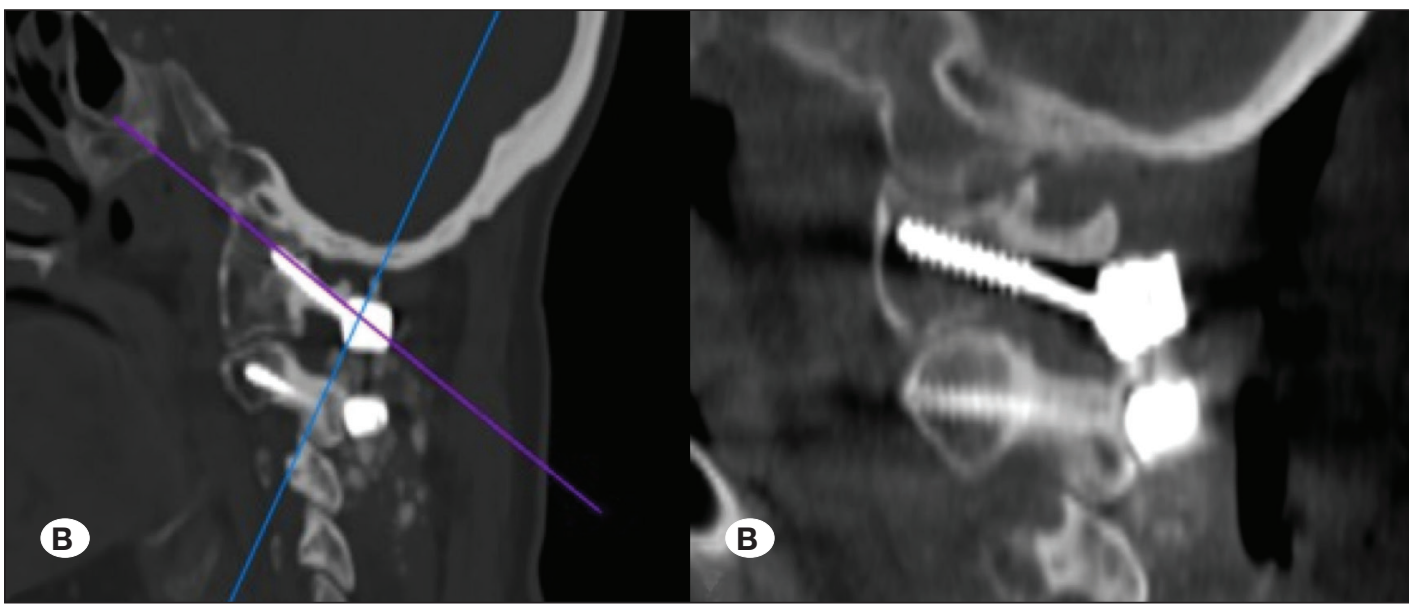

Figure 6: These figures are depicting case 3 . The right Atlas screw is too short and directed excessively cephalic (A), after revision (B). 
After 6 years, rods were removed owing to movement limitations and severe pain. Finally, 2 years later, he was operated using atlanto-occipital transarticular screws and occiput-C1-C2 fusion (Figure 7A-C). The reason of to include occiput to the fusion is maintaining instability. After the first revision, load carrying capacity of the upper cervical region and occipitocervical junction was not enough. After the first revision surgery, loosening of the screws developed. Atlantoaxial transarticular fixation was not provided an adequate stabilization.

\section{DISCUSSION}

Implant failure is one of the most important concerns after C1-2 fusion procedures. Thus, precautions and salvage procedures should be considered by all surgeons.

The main factor for implant failure is pseudoarthrosis (5). All operations were performed by decortication of the joints. Decortication should be done until haemorrhage from facet joints. This procedure may be dangerous and/or harmful to the small facets. This decortication is vital especially for nontraumatic distractive surgeries and in the cases that a small cage is inserted in the facet space. The second important precaution for pseudoarthrosis is using adequate autograft.

Several C1-C2 fixation techniques have been defined. Nevertheless, treating patients who require atlantoaxial fixation is surgically challenging. Excellent fusion rates and successful clinical outcomes need to be achieved. Notably, C1 lateral mass screws are inserted through the inferior base of the posterior arch of the atlas (11). When the C1 lateral mass screws are inserted directly in the lateral mass, the length of these screws is shorter than the $\mathrm{C} 1$ pedicle screws.
Fixation with screws has been evidenced to be more rigid than a fixation with wires (2). Notably, lateral segmental fusion could enable midline decompression if needed (3). Moreover, immediate stability can be achieved with screw fixation (17). Nonetheless, the older and safer technique of transarticular screw fixation might not be feasible in all patients who need C1-C2 fixation (16). Necessary of adding on the occiput to the fusion is a quite rare. Only if the atlanto-occipital joint is disruptive in an occipitocervical trauma or the occiput included atlantoaxial rotatory dislocation in children need occiput included fixation (10).

However, this challenging technique has some disadvantages. First, it requires detailed anatomical knowledge of the atlas and its surrounding anatomical structures. Moreover, VA is a crucial, restrictive structure (7). In addition, the proximity of the spinal cord and ICA to the $\mathrm{C} 1$ vertebra complicates the lateral mass screw placement. However, the VA injury rate associated with $\mathrm{C} 1$ screws is lower than that with transarticular screws (8). Moreover, a positional change of ICA at the anterior aspect of the atlas is another prominent risk factor of bicortical screws (1).

Ideal screw entry points and projection angles must be known by the surgeon. For a documented suggestion, one can consider the manuscript by Simsek et al (20).

Secondary AAl may develop owing to various pathologic conditions, including trauma, malformations, Down syndrome, rheumatoid arthritis, some infections, tumours and some craniovertebral junction anomalies (15). Notably, revision surgery is often required for these pathologies. Sample cases mentioned in the previous section reveal that revision surgery may be required immediately or after few years. Notably, most revision surgery requires changing the entry points and screw

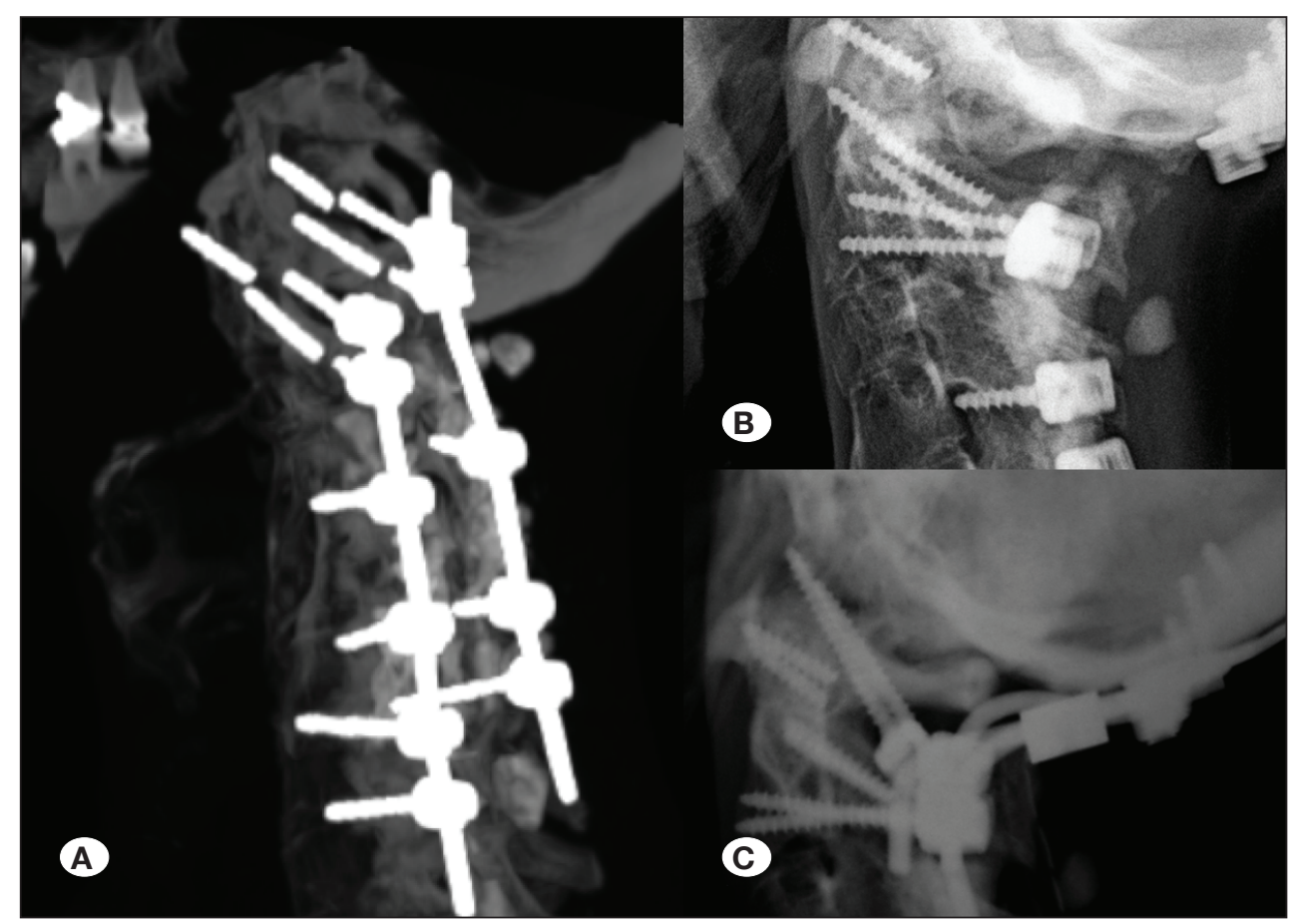

Figure 7: These figures are depicting case 4. Broken Atlas and Axis screws (A), after occipitocervical fixation and revision of $\mathrm{C} 2$ screws (B), after second revision with atlanto-occipital transarticular screw fixation and occiput-C1-C2 fusion (C). 
trajectory. Hence, the surgeon must have detailed anatomical knowledge and be aware of the dimensions of some structures to perform these changes safely. Moreover, knowing the screw lengths is crucial because of the proximity of the surgical region to ICA, VA and spinal cord. The present study results revealed that screw lengths become longer when the screws are directed cranially in the sagittal plane. By contrast, in the axial plane, the angular ranges of screws become narrower with the screws directed cranially in the sagittal plane.

Some anatomical studies in the literature revealed that the lateral masses of the atlas were larger than the pedicle of the axis (9). Therefore, the angular range of the atlas for revision screws is wider than the axis. Revision surgery was performed in the sample cases stated above after obtaining the measurements defined in the 'Methods' section. Therefore, screw placement does not require continuous fluoroscopy. Nevertheless, VA must be considered a major limiting structure, both laterally and superiorly. Studies have revealed that the atlas lateral mass screws are biomechanically superior to its alternatives, including transarticular screws and wiring techniques $(6,9,21)$. Moreover, it allows for a reduction after screw placement (18). Hence, the atlas lateral mass screws could be the preferable option for revision surgery in AAl.

\section{CONCLUSION}

Atlas lateral mass screws could be safely revised whenever needed. Nonetheless, possessing a detailed anatomical knowledge and performing the measurements defined in the present study facilitate safe revisions. The fact that needs to be considered is that the angular range becomes narrower, and the screw length becomes longer when the screw is directed more cranially.

\section{REFERENCES}

1. Currier BL, Todd LT, Maus TP, Fisher DR, Yaszemski MJ: Anatomic relationship of the internal carotid artery to the C1 vertebra: A case report of cervical reconstruction for chordoma and pilot study to assess the risk of screw fixation of the atlas. Spine 28:E461-E467, 2003

2. Dickman C, Crawford N, Paramore C: Biomechanical characteristics of C1-2 cable fixations. J Neurosurg 85:316322, 1996

3. Goel A, Desai KI, Muzumdar DP: Atlantoaxial fixation using plate and screw method: A report of 160 treated patients. Neurosurgery 51:1351-1356, 2002

4. Goel A, Laheri V: Plate and screw fixation for atlanto-axial subluxation. Acta Neurochir (Wien) 129:47-53, 1994

5. Grob D, Jeanneret B, Aebi M, Markwalder TM: Atlanto-axial fusion with transarticular screw fixation. J Bone Joint Surg $\mathrm{Br}$ 73(6):972-976, 1991
6. Grob D: Transarticular screw fixation for atlanto-occipital dislocation. Spine 24:703-707, 2001

7. Gupta T: Cadaveric morphometric anatomy of C-1 vertebra in relation to lateral mass screw placement. Surg Radiol Anat 30:589-593, 2008

8. Harms J, Melcher RP: Posterior C1-C2 fusion with polyaxial screw and rod fixation. Spine (Phila Pa 1976) 26:2467-2471, 2001

9. Hong X, Dong Y, Yunbing C, Quingshui Y, Shizheng Z, Jingfa $\mathrm{L}$ : Posterior screw placement on the lateral mass of atlas: An anatomic study. Spine 29:500-503, 2004

10. Kim JH, Kim JH, Jang SY, Kong MH: Combined chronic occipito-atlantal and atlanto-axial rotator fixation with cerebral palsy. Korean J Spine 10(3):192-194, 2013

11. Ma XY, Yin QS, Wu ZH, Xia H, Liu JF, Zhong SZ: Anatomic considerations for the pedicle screw placement in the first cervical vertebra. Spine 30:1519-1523, 2005

12. Magerl F, Seemann PS: Stable posterior fusion at the atlas and axis by transarticular screw fixation. In: Kehr P, Weidner A (eds), Cervical Spine I. Springer, Wien, 1987:322-327

13. Mandel IM, Kambach BJ, Petersilge CA, Johnstone B, Yoo $\mathrm{JU}$ : Morphologic considerations of $\mathrm{C} 2$ isthmus dimensions for the placement of transarticular screws. Spine (Phila Pa 1976) 25:1542-1547, 2000

14. Melcher RP, Puttlitz CM, Kleinstueck FS, Lotz JC, Harms J, Bradford DS: Biomechanical testing of posterior atlantoaxial fixation techniques. Spine 27:2435-2440, 2002

15. Menezes $\mathrm{AH}$ : Craniovertebral junction anomalies: Diagnosis and management. Semin Pediatr Neurol 4:209-223, 1997

16. Paramore C, Dickman C, Sonntag V: The anatomical suitability of the C1-2 complex for transarticular screw fixation. J Neurosurg 85:221-224, 1996

17. Resnick DK, Lapsiwala S, Trost GR: Anatomic suitability of the C1-C2 Complex for pedicle screw fixation. Spine 27:14941498, 2002

18. Ringel F, Reinke A, Stüer C, Meyer B, Stoffel M: Posterior C1-2 fusion with $\mathrm{C} 1$ lateral mass and $\mathrm{C} 2$ isthmic screws: Accuracy of screw position, alignment and patient outcome. Acta Neurochir 154:305-312, 2012

19. Rocha R, Safavi-Abbasi S, Reis C, Theodore N, Bambakidis N, Oliveira E, Sonntag VKH, Crawford NR: Working area, safety zones, and angles of approach for posterior C-1 lateral mass screw placement: A quantitative anatomical and morphometric evaluation. J Neurosurg Spine 6:247-254, 2007

20. Simsek S, Yigitkanli K, Seckin H, Comert A, Acar HI, Belen D, Tekdemir I, Elhan A: Ideal screw entry point and projection angles for posterior lateral mass fixation of the atlas: An anatomical study. Eur Spine J 18(9):1321, 2009

21. Yi P, Dong L, Tan M, Wang W, Tang X, Yang F, Zhang G: Clinical application of a revised screw technique via the $c 1$ posterior arch and lateral mass in the pediatric population. Pediatr Neurosurg 49:159-165, 2013 